\title{
Low Serum Testosterone Concentration in Middle-aged Men with Type 2 Diabetes
}

\author{
MiCHIAKI FUKUI, JINTETSU SOH*, MUHEI TANAKA, YOSHIHIRO KITAGAWA**, GOJI HASEGAWA, \\ TOSHIKAZU YOSHIKAWA***, TSUNEHARU MIKI* AND NAOTO NAKAMURA
}

Department of Endocrinology and Metabolism, Kyoto Prefectural University of Medicine, Graduate School of Medical Science, 465 Kajii-cho, Kawaramachi-Hirokoji, Kamigyo-ku, Kyoto 602-8566, Japan

*Department of Urology, Kyoto Prefectural University of Medicine, Graduate School of Medical Science, 465 Kajii-cho, KawaramachiHirokoji, Kamigyo-ku, Kyoto 602-8566, Japan

**Department of Endocrinology and Hematology, Osaka General Hospital of West Japan Railway Company, 1-2-22 Matsuzaki-cho, Abeno-ku, Osaka 545-0053, Japan

***Department of Inflammation and Immunology, Kyoto Prefectural University of Medicine, Graduate School of Medical Science, 465 Kajii-cho, Kawaramachi-Hirokoji, Kamigyo-ku, Kyoto 602-8566, Japan

\begin{abstract}
Low concentrations of endogenous androgens have been linked with insulin resistance and atherosclerosis. Men with diabetes have been reported to have lower serum testosterone concentration than non-diabetic men; however, there has never been a large study. The aim of this study was to investigate if endogenous androgen concentration is certainly lower in a relatively large number of Japanese patients with type 2 diabetes compared with healthy men, and to identify what factors may be associated with low serum testosterone concentrations in men with type 2 diabetes. Serum free testosterone concentrations were measured in 524 healthy men and in 331 consecutive Japanese men with type 2 diabetes between 40 and 69 years old. In addition, we investigated the relationships between serum free testosterone concentration and luteinizing hormone ( $\mathrm{LH})$ concentration as well as major cardiovascular risk factors including age, blood pressure, plasma lipid concentration, glycemic control $\left(\mathrm{HbA}_{1 \mathrm{c}}\right)$, and BMI. Serum free testosterone concentrations were lower in men with type 2 diabetes than in healthy men in the 40-49 years group $(10.9 \pm 3.3 v s .14 .0 \pm 3.6 \mathrm{pg} / \mathrm{ml}$, $P<0.0001)$, in the 50-59 years group $(10.4 \pm 3.2 v s .12 .1 \pm 2.9 \mathrm{pg} / \mathrm{ml}, P<0.0001)$, and in the 60-69 years group $(9.5 \pm 2.6$ vs. $10.5 \pm 2.9 \mathrm{pg} / \mathrm{ml}, P=0.0104)$. A negative correlation was found between serum free testosterone and $\mathrm{LH}$ concentrations $(\mathrm{r}=-0.326, P<0.0001)$. In conclusion, serum free testosterone concentration is certainly lower in a relatively large number of Japanese patients with type 2 diabetes compared with healthy men with each decade of life between 40 and 69 years old.
\end{abstract}

Key words: Testosterone, Luteinizing Hormone, Type 2 diabetes, Men

(Endocrine Journal 54: 871-877, 2007)

LOW concentrations of endogenous androgens have been linked with insulin resistance, which is an important upstream driver for metabolic abnormalities such as hyperglycemia, hypertension, or dyslipidemia, and increased cardiovascular risk $[1,2]$. Moreover, results

Received: May 9, 2007

Accepted: September 3, 2007

Correspondence to: Michiaki FUKUI, M.D., Department of Endocrinology and Metabolism, Kyoto Prefectural University of Medicine, Graduate School of Medical Science, 465 Kajii-cho, Kawaramachi-Hirokoji, Kamigyo-ku, Kyoto 602-8566, Japan from the Massachusetts Male Aging Study suggested that low concentrations of testosterone might play a role in the development of insulin resistance and subsequent type 2 diabetes [3]. Keating et al. [4] recently demonstrated that androgen deprivation therapy is associated with an increased incidence of diabetes and cardiovascular disease (CVD). On the other hand, administration of testosterone to hypogonadal middleaged men improved insulin sensitivity and glucose homeostasis $[5,6]$. Studies in laboratory animals support the hypothesis that diabetes has a detrimental effect on testicular function; reductions in both Leydig cell num- 
ber and testosterone secretion have been reported [7].

Men with diabetes have been reported to have lower serum testosterone concentrations than non-diabetic men $[8,9]$. However, there has never been a large scale study of serum testosterone concentration in men with type 2 diabetes. Previous reports had small numbers of patients and did not investigate much about what factors may be associated with low serum testosterone concentrations in patients with type 2 diabetes. Recently, the Endocrine Society Clinical Practice Guideline demonstrated that men with type 2 diabetes is one of the conditions in which there is a high prevalence of low serum testosterone concentration and in which the guideline recommend measurement of serum testosterone concentration [10].

In this study, we investigated if endogenous androgen concentration is certainly lower in a relatively large number of Japanese patients with type 2 diabetes compared with healthy men, and identified what factors may be associated with low serum testosterone concentrations in men with type 2 diabetes.

\section{Materials and Methods}

\section{Subjects}

Serum free testosterone concentrations were measured in 524 healthy men who underwent general health screening tests and in 331 consecutive Japanese men with type 2 diabetes between 40 and 69 years old recruited from outpatient clinics of Kyoto Prefectural University of Medicine and Osaka General Hospital of West Japan Railway Company. The number of subjects in the 40-49 years, 50-59 years, and 60-69 years age group were 235,169 , and 120 among 524 healthy men. The number of subjects in the $40-49$ years, 50 59 years, and 60-69 years age group were 39,173 , and 119 among 331 men with type 2 diabetes. In addition, we investigated the relationships between serum free testosterone and luteinizing hormone (LH) concentrations in a subgroup of 154 randomly selected diabetic patients as well as between serum free testosterone concentrations and major cardiovascular risk factors including age, blood pressure, plasma lipid concentration, glycemic control $\left(\mathrm{HbA}_{1 \mathrm{c}}\right)$, and BMI, severity of diabetic retinopathy, severity of diabetic nephropathy, current treatment for diabetes, presence of hypertension, presence of dyslipidemia, or presence of CVD.
Serum free testosterone concentrations (normal ranges: 14.0 to $40.0 \mathrm{pg} / \mathrm{ml}$ ) were measured by the CoatA-Count free and total testosterone kit (Diagnostic Products Corporation, Los Angeles, CA, USA). The intra-assay coefficients of variance $(\mathrm{CV})$ were 10.0 , 6.0 , and $5.0 \%$, for free testosterone concentrations of $1.87,11.8$, and $38.7 \mathrm{pg} / \mathrm{ml}$, respectively. The interassay CV were $21.0,8.0$, and $7.0 \%$, for free testosterone concentrations of $1.38,11.03$, and $37.3 \mathrm{pg} / \mathrm{ml}$, respectively. Serum LH concentrations (normal ranges: 0.79 to $5.72 \mathrm{mIU} / \mathrm{ml}$ ) were measured by chemiluminescent immunoassay on an ARCHITECT automated analyzer (Abbott Laboratories Diagnostic Division, IL, USA). The intra-assay CV were 5.68, 3.37, and 3.11\%, for $\mathrm{LH}$ concentrations of 7.37, 24.6, and $102 \mathrm{mIU} / \mathrm{ml}$, respectively. The inter-assay CV were $5.43,2.60$, and $1.64 \%$, for $\mathrm{LH}$ concentrations of $6.84,23.3$, and $98.3 \mathrm{mIU} / \mathrm{ml}$, respectively. Plasma total cholesterol, HDL cholester$\mathrm{ol}$, and triglyceride concentrations were assessed using standard enzymatic methods. $\mathrm{HbA}_{1 \mathrm{c}}$ was assayed using high-performance liquid chromatography.

Type 2 diabetes was diagnosed according to the Report of the Expert Committee on the Diagnosis and Classification of Diabetes Mellitus [11]. Retinopathy was graded as follows: no diabetic retinopathy, NDR; simple diabetic retinopathy, SDR; and proliferative diabetic retinopathy, PDR. Nephropathy was graded as follows: normoalbuminuria, urinary albumin excretion less than $30 \mathrm{mg}$ per gram of creatinine $(\mathrm{mg} / \mathrm{g} \mathrm{Cr})$; microalbuminuria, 30 to $300 \mathrm{mg} / \mathrm{g} \mathrm{Cr}$; or macroalbuminuria, more than $300 \mathrm{mg} / \mathrm{g} \mathrm{Cr}$. In patients with type 2 diabetes, mean values for biochemical parameters obtained during the preceding year were used for statistical analysis. Hypertension was defined as blood pressure of at least 140/90 $\mathrm{mmHg}$ or use of antihypertensive medication. Dyslipidemia was defined as total cholesterol exceeding $220 \mathrm{mg} / \mathrm{dL}$, triglyceride exceeding $150 \mathrm{mg} / \mathrm{dL}$, or use of antihyperlipidemic medication. CVD was defined as the presence of previous myocardial infarction or cerebral infarction based on the clinical history or physical examination.

Patients were excluded if they had been castrated for the treatment of testicular or prostate cancer, or were taking any medications known to affect sex hormone concentrations (e.g., antiandrogenic agents for prostate cancer). Approval for the study was obtained from the local Research Ethics Committee, and informed consent was obtained from all participants. 


\section{Statistical analysis}

Means or frequencies of potential confounding variables were calculated as appropriate. Unpaired Student's t tests or analyses of variance (ANOVA) were conducted to assess statistical significance of differences between groups using Stat View software (version 5.0; SAS Institute, Cary, NC). A two-factor ANOVA was used to determine the effect of diabetes adjusted for age on serum free testosterone concentrations. Correlations between serum free testosterone concentration and LH concentration as well as age, blood pressure, serum lipid concentration, and glycemic control $\left(\mathrm{HbA}_{1 \mathrm{c}}\right)$, BMI, or other variables were examined by linear regression analysis. All continuous variables are presented as the mean $\pm \mathrm{SD}$. A P value $<0.05$ was considered statistically significant.

\section{Results}

The clinical characteristics of the 331 men with type 2 diabetes enrolled in this study are shown in Table 1. The mean serum free testosterone concentration was $10.1 \pm 3.0 \mathrm{pg} / \mathrm{ml}$.

Serum free testosterone concentrations were lower in men with type 2 diabetes than in healthy men in the

Table 1. Clinical characteristics of patients with diabetes

\begin{tabular}{lc}
\hline & Mean $\pm \mathrm{SD}$ \\
\hline $\mathrm{n}$ & 331 \\
Age (years) & $57.5 \pm 6.8$ \\
Age at onset (years) & $46.6 \pm 10.2$ \\
Duration of diabetes (years) & $11.2 \pm 9.4$ \\
$\mathrm{BMI}\left(\mathrm{kg} / \mathrm{m}^{2}\right)$ & $23.6 \pm 3.2$ \\
$\mathrm{HbA}_{1 \mathrm{c}}(\%)$ & $7.2 \pm 1.2$ \\
Systolic blood pressure (mm Hg) & $134 \pm 15$ \\
Diastolic blood pressure (mm Hg) & $80 \pm 9$ \\
Total cholesterol (mmol/l) & $5.12 \pm 0.83$ \\
Triglyceride (mmol/l) & $1.71 \pm 0.95$ \\
HDL-cholesterol (mmol/l) & $1.37 \pm 0.39$ \\
Smoking (none/past/current) & $67 / 125 / 139$ \\
Retinopathy (NDR/SDR/PDR) & $224 / 47 / 60$ \\
Nephropathy (normo-/micro-/macroalbuminuria) & $209 / 74 / 48$ \\
Cadiovascular disease (-/+) & $294 / 37$ \\
Current treatment (Diet/OHA/Insulin) & $40 / 214 / 77$ \\
Free testosterone (pg/ml) & $10.1 \pm 3.0$ \\
\hline
\end{tabular}

NDR, no diabetic retinopathy; SDR, simple diabetic retinopathy; PDR, proliferative diabetic retinopathy; OHA, oral hypoglycemic agents.
40-49 years group $(10.9 \pm 3.3$ vs. $14.0 \pm 3.6 \mathrm{pg} / \mathrm{ml}$, $P<0.0001$ after adjustment for age), in the 50-59 years group $(10.4 \pm 3.2$ vs. $12.1 \pm 2.9 \mathrm{pg} / \mathrm{ml}, P<0.0001$ after adjustment for age), and in the 60-69 years group $(9.5 \pm 2.6 v s .10 .5 \pm 2.9 \mathrm{pg} / \mathrm{ml}, P=0.0104$ after adjustment for age; Fig. 1).

Negative correlations were found between serum free testosterone concentration and age $(\mathrm{r}=-0.214$, $P<0.0001)$, and age at onset $(\mathrm{r}=-0.121, P=0.0354)$. A positive correlation was found between serum free testosterone and total cholesterol concentrations $(\mathrm{r}=$ $0.140, P=0.0108)$. No correlations were found between serum free testosterone and duration of diabetes $(\mathrm{r}=-0.036, P=0.5281)$, BMI $(\mathrm{r}=0.077, P=0.1718)$, HbA1c $(\mathrm{r}=0.066, P=0.2328)$, systolic blood pressure $(\mathrm{r}=-0.008, P=0.8864)$, diastolic blood pressure $(\mathrm{r}=$ $0.084, P=0.1343)$, plasma triglyceride $(\mathrm{r}=0.030, P=$ $0.5819)$, and HDL-cholesterol $(\mathrm{r}=0.021, P=0.7064)$. A negative correlation was found between serum free testosterone and $\mathrm{LH}$ concentrations $(\mathrm{r}=-0.326, P<$ 0.0001; Fig. 2).

Serum free testosterone concentrations did not differ between patients with or without hypertension $(10.1 \pm$ 2.9 vs. $10.3 \pm 3.3 \mathrm{pg} / \mathrm{ml}, P=0.4926)$, dyslipidemia $(10.3 \pm 3.1$ vs. $10.1 \pm 3.0 \mathrm{pg} / \mathrm{ml}, P=0.6360)$, or CVD $(10.0 \pm 3.4$ vs. $10.2 \pm 3.0 \mathrm{pg} / \mathrm{ml}, P=0.7028)$. In addition, serum free testosterone concentrations did not differ between patients treated with or without insulin

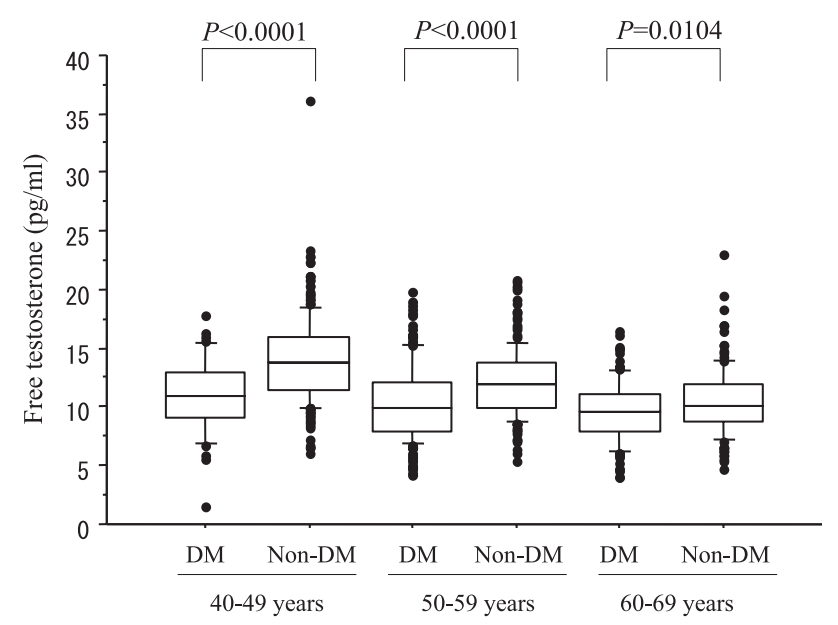

Fig. 1. Comparison of serum free testosterone concentrations in men with type 2 diabetes (DM) and in healthy men (Non-DM) with each decade of life between 40 and 69 years old. Data are presented as medians, 25th and 75th percentiles (boxes), and 10th and 90th percentiles (whiskers). 


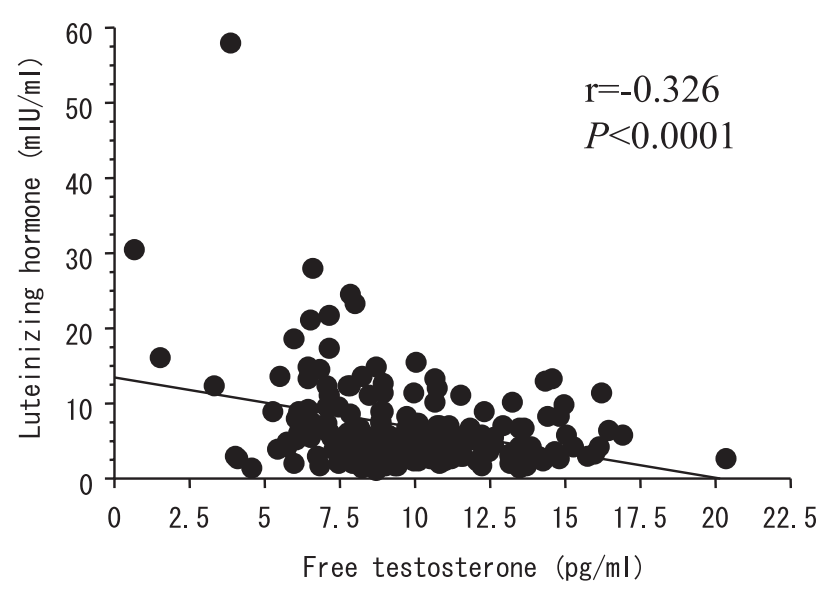

Fig. 2. Correlation between serum free testosterone and luteinizing hormone concentrations in men with type 2 diabetes.

$(9.9 \pm 2.9$ vs. $10.2 \pm 3.1 \mathrm{pg} / \mathrm{ml}, P=0.4894)$. Serum free testosterone concentrations did not differ based on the severity of diabetic nephropathy $(10.2 \pm 3.2 \mathrm{vs}$. $10.2 \pm 2.5 v s .9 .8 \pm 3.2 \mathrm{pg} / \mathrm{ml}$ for patients with normoalbuminuria, microalbuminuria, or macroalbuminuria, respectively). Serum free testosterone concentrations was lower in patients with PDR $(9.4 \pm 3.1 \mathrm{pg} / \mathrm{ml})$ than in patients with NDR $(10.4 \pm 2.9 \mathrm{pg} / \mathrm{ml}, P=0.0452)$, and than in patients with SDR $(11.1 \pm 3.6 \mathrm{pg} / \mathrm{ml}$, $P=0.0105$ ). Serum free testosterone concentrations did not differ among patients with nonsmoker, past smoker, or current smoker $(10.4 \pm 3.4 v s .9 .9 \pm 2.7 v s$. $10.5 \pm 3.1 \mathrm{pg} / \mathrm{ml}$, respectively).

\section{Discussion}

In the present study, we demonstrated that serum free testosterone concentration is significantly lower in a relatively large number of Japanese patients with type 2 diabetes compared with healthy men with each decade of life between 40 and 69 years old.

Moreover, we demonstrated a negative correlation between serum free testosterone and LH concentrations, which indicated hypergonadtropic hypogonadism in men with type 2 diabets. Ando et al. [12] also demonstrated that lower serum free testosterone and higher LH concentrations in men with type 2 diabetes compared with control subjects. The present study is not in line with recent report by Dhindsa et al. [13] demonstrating serum LH concentrations correlated positively with serum free testosterone concentra- tions (hypogonadotropic hypogonadism) in men with type 2 diabetes. A possible explanation is that mean BMI is much higher in their patients compared with ours $\left(33.4 v s .23 .6 \mathrm{~kg} / \mathrm{m}^{2}\right)$. In obese men there is a decrease in free testosterone concentration, resulting from the peripheral conversion of testosterone into estrogen, which decreases the amplitude of LH pulse, promoting central inhibition of androgenic production [14]. It is also possible that the decreased concentrations of testosterone in obese men result from an inhibitory effect of leptin on the hypothalamus-pituitarygonadal axis [15]. Obesity is associated with increased plasma levels of proinflammatory cytokines such as tumor necrosis factor (TNF)- $\alpha$, interleukin (IL)-6, Creactive protein, and adhesion molecules [16]. TNF- $\alpha$ and IL-1 $\beta$ have been shown to reduce hypothalamic LH secretion in animals and in vitro $[17,18]$. Dhindsa et al. also demonstrated that LH levels were significantly lower in obese men.

We examined a number of possible explanations for the lower serum testosterone concentrations in middleaged men with type 2 diabetes. In this study, both agespecific and age-adjusted analyses showed that age did not explain the lower serum testosterone concentrations observed in men with type 2 diabetes. Studies in laboratory animals support the hypothesis that diabetes has a detrimental effect on testicular function; reductions in both Leydig cell number and testosterone secretion have been reported [7]. The association between glycemia and reduced testosterone concentration may be an effect of glycemia on the testicular microvasculature. Data from animal studies support the hypothesis that glycemia alters Leydig cell function directly. The inverse association of serum testosterone concentration and plasma glucose concentration was also observed in those without diabetes $[1,2]$. BMI, smoking status, or alcohol consumption might influence the difference of serum free testosterone concentration between men with type 2 diabetes and healthy men. However, BMI and smoking status were not associated with serum free testosterone concentration among men with type 2 diabetes. Moreover, treatment for diabetes, hypertension, and hyperlipidemia might influence the results, although serum free testosterone concentration was not differ between patients treated with and without insulin. Our study demonstrated a positive correlation between total cholesterol and free testosterone concentrations. Because cholesterol is the immediate biosynthetic precursor of steroids, the re- 
duction in cholesterol concentration associated with statin therapy could be the cause of the reductions in hormone.

The cutoff values for serum testosterone levels in diagnosing hypogonadism differ among institutions and research groups. Nakazawa et al. [19] regarded a serum free testosterone concentration less than $10 \mathrm{pg} / \mathrm{ml}$ as indicating hypogonadism. According to their cutoff value, the prevalence of hypogonadism was $35.9 \%$ in the $40-49$ years group, $48.0 \%$ in the $50-59$ years group, and $58.8 \%$ in the $60-69$ years group in men with type 2 diabetes. Interestingly, there was no significant difference between serum free testosterone concentration in the 50-59 years age group in men with type 2 diabetes $(10.4 \pm 3.2 \mathrm{pg} / \mathrm{ml})$ and that in the 60-69 years age group in healthy men $(10.5 \pm 2.9 \mathrm{pg} / \mathrm{ml})$.

The present study demonstrated no association between serum free testosterone concentration and the severity of diabetic nephropathy. However, serum free testosterone was lower in patients with progressed diabetic retinopathy. Loss of retinal capillary pericytes, a characteristic change in the early phase of diabetic retionopathy, is considered a key step in retinopathy progression [20]. Brignardello et al. [21] demonstrated that by its antioxidant properties, dehydroepiandrosterone (DHEA), which is a weak androgen that contributes to androgenicity mainly after peripheral convesion to testosterone, prevents suppression of retinal capillary pericyte growth caused by excessive glucose.

We compared serum free testosterone rather than total testosterone concentration in men with type 2 diabetes and healthy men because free testosterone concentration is a more sensitive and active marker for insulin resistance or atherosclerosis in previous studies compared with total testosterone. Rhoden et al. [22] also demonstrated that subnormal free testosterone concentration had a stronger correlation with the presence of diabetes mellitus than subnormal total testosterone concentration.

Limitation of the present study was that serum free testosterone concentration was measured by radioimmunoassay (RIA), a method that has been criticized for its variability [23]. Unfortunately, equilibrium dialysis, a method considered to be the gold standard for measuring serum free testosterone concentration, was not available. Nevertheless, the present study is unique in comparing serum free testosterone concentration in diabetic and nondiabetic middle-aged men. Despite the limitation of RIA for measuring serum free tes- tosterone concentration, we believe that the main findings of the present study are valid, considering that the presence of a nondiabetic control group has reduced associated biases. Although, equilibrium dialysis is thought to be the best method for measuring serum free testosterone concentration, the International Society for the Study of the Aging Male (ISSAM) recommended calculated free testosterone as a standard diagnostic indicator for partial androgen deficiency in aging males (PADAM) because equilibrium dialysis is a delicate, expensive, and time-consuming technique and therefore not suitable for population-based or large studies [24]. In Japan, sex hormone binding globulin (SHBG) measurement is uncommon because SHBG is not approved under the medical care system. At present, RIA is the only available measurement for serum free testosterone concentration. Okamura et al. [25] demonstrated a significantly positive relationship between serum free testosterone concentration measured by RIA and calculated free testosterone concentration. We believe that serum free testosterone concentration determined by RIA would be useful for identifying hypogonadism for large studies.

Men with diabetes have significantly lower serum testosterone concentration than non-diabetic men. Low concentrations of endogenous androgens have been linked with increased cardiovascular risk The increased risk for CVD in diabetic men could be partially mediated through low concentrations of testosterone. Increased age is one of the strongest predictors for coronary artery disease. The Telecom Study demonstrated a significant decrease in testosterone concentration with each decade of life [26]. Both mean intima-media thickness and plaque score, determined by carotid ultrasonography, have been proven to be inversely associated with serum free testosterone concentration in our previous study [27].

Hypogonadism is associated with an increase in fat mass, decreased muscle mass, accelerated bone loss, and decreased libido, which would be improved by treatment with testosterone [28]. Moreover, hypogonadism is associated with increased insulin resistance and progression of atherosclerosis [2, 29]. Because men with type 2 diabetes have relative hypogonadism, supplementation with androgen might reduce both insulin resistance and atherosclerosis. Life-style changes could be a logical first-line treatment in many ventrally obese men with andropause. Weight loss is important in prevention of progressive metabolic decompensa- 
tion and CVD associated with obesity and the metabolic syndrome. While a number of preparations are available for testosterone replacement, little is known about suitability or efficacy of individual preparations for protection from insulin resistance or atherosclerosis. Long-term trials of testosterone replacement therapy are needed to assess both efficacy and safety.

In conclusion, serum free testosterone concentration is certainly lower in a relatively large number of Japanese patients with type 2 diabetes compared with healthy men. The clinical and physiologic implications of the reduced serum testosterone concentrations in diabetic men merit further investigation.

\section{Acknowledgement}

We would like to thank Dr. Teruaki Iwamoto and Dr. Katsuyuki Baba (Department of Urology, St. Marianna University School of Medicine), Dr. Toshihiko Yanase and Dr. Hajime Nawata (Department of Medicine and Bioregulatory Science, Graduate School of Medical Science, Kyushu University), Dr. Eitetsu Koh and Dr. Mikio Namiki (Department of Integrative Cancer Therapy and Urology, Kanazawa University Graduate School of Medical Science), and Dr. Hitoshi Horie (Mitsubishi Kagaku Bio-Clinical Laboratories, INC) for kindly providing us the data of healthy men.

\section{References}

1. Simon D, Charles MA, Nahoul K, Orssaud G, Kremski J, Hully V, Joubert E, Papoz L, Eschwege E (1997) Association between plasma total testosterone and cardiovascular risk factors in healthy adult men: The Telecom Study. J Clin Endocrinol Metab 82: 682-685.

2. Haffner SM, Karhapaa P, Mykkanen L, Laakso M (1994) Insulin resistance, body fat distribution and sex hormones in men. Diabetes 43: 12-19.

3. Stellato RK, Feldman HA, Hamdy O, Horton ES, McKinlay JB (2000) Testosterone, sex hormone-binding globlin, and the development of type 2 diabetes in middle-aged men. Diabetes Care 23: 490-494.

4. Keating NL, O’Malley AJ, Smith MR (2006) Diabetes and cardiovascular disease during androgen deprivation therapy for prostate cancer. J Clin Oncol 24: 4448-4456.

5. Marin P, Holmang S, Jonsson L, Sjostrom L, Kvist H, Holm G, Lindstedt G, Bjorntorp P (1992) The effects of testosterone treatment on body composition and metabolism in middle-aged obese men. Int J Obes Relat Metab Disord 16: 991-997.

6. Boyanov MA, Boneva Z, Christov VG (2003) Testosterone supplementation in men with type 2 diabetes, visceral obesity and partial androgen deficiency. Aging Male 6: 1-7.

7. Jackson FL, Hutson JC (1984) Altered responses to androgen in diabetic male rats. Diabetes 33: 819-824.

8. Andersson B, Marin P, Lissner L, Vermeulen A, Bjorntorp P (1994) Testosterone concentrations in women and men with NIDDM. Diabetes Care 17: 405-411.

9. Barrett-Connor E (1992) Lower endogenous androgen levels and dyslipidaemia in men with NIDDM. Ann Intern Med 117: 807-811.

10. Bhasin S, Cunningham GR, Hayes FJ, Matsumoto AM, Snyder PJ, Swerdloff RS, Montori VM (2006) Testos- terone therapy in adult men with androgen deficiency syndromes: an Endocrine Society Clinical Practice Guideline. J Clin Endocrinol Metab 91: 1995-2010.

11. The Expert Committee on the Diagnosis and Classification of Diabetes Mellitus (2002) Report of the expert committee on the diagnosis and classification of diabetes mellitus. Diabetes Care 25: S5-S20.

12. Ando S, Rubens R, Rottiers R (1984) Androgen plasma levels in male diabetics. J Endocrinol Invest 7: 21-24.

13. Dhindsa S, Prabhakar S, Sethi M, Bandyopadhay A, Chaudhuri A, dandona P (2004) Frequent occurrence of hypogonadotropic hypogonadism in type 2 diabetes. J Clin Endocrinol Metab 89: 5462-5468.

14. Vermeulen A, Kaufman JM, Deslypere JP, Thomas G (1993) Attenuated luteinizing hormone (LH) pulse amplitude but normal LH pulse frequency, and its relation to plasma androgens in hypogonadism of obese men. $J$ Clin Endocrinol Metab 76: 1140-1146.

15. Isidori AM, Caprio M, Strollo F, Moretti C, Frajese G (1999) Leptin and androgens in male obesity: evidence for leptin contribution to reduced androgen levels. $J$ Clin Endocrinol Metab 84: 3673-3680.

16. Weisberg SP, McCann D, Desai M, Rosenbaum M, Leibel RL, Ferrante Jr. AW (2003) Obesity is associated with macrophage accumulation in adipose tissue. $J$ Clin Invest 112: 1796-1808.

17. Watanobe H, Hayakawa Y (2003) Hypothalamic interleukin- $\beta$ and tumor necrosis factor- $\alpha$, but not interleukin-6, mediate the endotoxin-induced suppression of the reproductive axis in rats. Endocrinology 144: 4868-4875.

18. Russel SH, Small CJ, Stanley SA, Franks S, Ghatei MA, Bloom SR (2001) The in vitro role of tumour necrosis factor- $\alpha$ and interleukin- 6 in the hypothalamicpituitary gonadal axis. J Neuroendocrinol 13: 296-301.

19. Nakazawa R, Baba K, Nakano M, Katabami T, Saito 
N, Takahashi T, Iwamoto T (2006) Hormone profiles after intramuscular injection of testosterone enanthate in patients with hypogonadism. Endocr J 53: 305-310.

20. Kefalides NA (1981) Basement membrane research in diabetes mellitus. Coll Relat Res 1: 295-299.

21. Brignardello E, Beltramo E, Molinatti PA, Aragno M, Gatto V, Tamagno E, Danni O, Porta M, Boccuzzi G (1998) Dehydroepiandrosterone protects bovine retinal capillary pericytes against glucose toxicity. $J$ Endocrinol 58: 21-26.

22. Rhoden EL, Ribeiro EP, Teloken C, Souto CAV (2005) Diabetes mellitus is associated with subnormal serum levels of free testosterone in men. BJU Int 96: 867870.

23. Rosner W (1997) Errors in the measurement of plasma free testosterone. J Clin Endocrinol Metab 82: 20142015.

24. Morales A, Lunenfeld B, International Society for the Study of the Aging Male (2002) Investigation, treatment and monitoring of late-onset hypogonadism in males. Official recommendations of ISSAM. Aging
Male 5: 74-86.

25. Okamura K, Ando F, Shimokata H (2005) Serum total and free testosterone level of Japanese men: a population-based study. Int J Urol 12: 810-814.

26. Simon D, Preziosi P, Barrett-Connor E, Roger M, SaitPaul M, Nahoul K, Papoz L (1992) The influence of ageing on plasma sex hormones in men. The Telecom Study. Am J Epidemiol 135: 783-791.

27. Fukui M, Kitagawa Y, Nakamura N, Kadono M, Mogami S, Hirata C, Ichio N, Wada K, Hasegawa G, Yoshikawa T (2003) Association between serum testosterone concentration and carotid atherosclerosis in men with type 2 diabetes. Diabetes Care 26: 1869 1873.

28. Bhasin S (2003) Effects of testosterone administration on fat distribution, insulin sensitivity, and atherosclerosis progression. Clin Infect Dis 37: S142-S149.

29. Muller M, van den Beld AW, Bots ML, Grobbee DE, Lamberts SW, van der Schouw YT (2004) Endogenous sex hormone and progression of carotid atherosclerosis in elderly men. Circulation 109: 2074-2079. 